\title{
Occurrence, distribution and seasonal variation of organophosphate flame retardants and plasticizers in urban surface water in Beijing, China
}

\author{
Yali Shi ${ }^{\text {a }}$, Lihong Gao ${ }^{\text {a, b }}$, Wenhui Li ${ }^{\text {b }}$, Yuan Wang ${ }^{\text {a }}$, Jiemin Liu ${ }^{\text {b }}$, Yaqi Cai ${ }^{\text {a, c, * }}$ \\ a State Key Laboratory of Environmental Chemistry and Ecotoxicology, Research Center for Eco-Environmental Sciences, Chinese Academy of Sciences, \\ Beijing, 100085, China \\ ${ }^{\mathrm{b}}$ Civil and Environment Engineering School, University of Science and Technology Beijing, Beijing, 100083, China \\ c Institute of Environment and Health, Jianghan University, Wuhan, 430056, China
}

\section{A R T I C L E I N F O}

\section{Article history:}

Received 9 July 2015

Received in revised form

5 November 2015

Accepted 5 November 2015

Available online 7 December 2015

\section{Keywords:}

Organophosphate esters (OPEs)

Surface water

Occurrence

Spatial distribution and seasonal variation

Risk assessment

\begin{abstract}
A B S T R A C T
The occurrence, spatial distribution and seasonal variation of 14 organophosphate esters (OPEs) were investigated in urban surface water (river and lake water) from July 2013 to June 2014 in Beijing, China. Sewage influent and effluent samples, as well as rainwater and road runoff samples were also analyzed as the potential sources of OPEs in surface water. Tris(2-chloro-1-methylethyl) phosphate (TCPP) and tris(2chloroethyl) phosphate (TCEP) were the most abundant OPEs with the average concentrations of $291 \mathrm{ng} \mathrm{L}^{-1}$ and $219 \mathrm{ng} \mathrm{L}^{-1}$, respectively. Relatively high concentrations of OPEs were detected in rivers located at southern and eastern urban of Beijing, which was probably attributed to the treated and untreated sewage discharge. Besides, higher levels of OPEs were observed in urban surface water in the summer, and the wet deposition (rainfall) was confirmed to be an important factor for this observation. Risk assessment showed low or medium risk of OPEs for the organisms (algae, crustacean and fish).
\end{abstract}

(c) 2015 Elsevier Ltd. All rights reserved.

\section{Introduction}

As the major replacement for polybrominated diphenyl ethers (PBDEs), organophosphate esters (OPEs) are utilized as flame retardants in a large variety of consumer products such as plastics, textiles, electronic equipment, industrial materials and furniture (Reemtsma et al., 2008; Yang et al., 2014). Chlorinated-OPEs are the predominant compounds for this application (Reemtsma et al., 2008). Apart from being used as flame retardants, OPEs are also applied as plasticizers, antifoaming or anti-wear agents in lacquers, hydraulic fluids, floor polishing agents, and non-ionic extractants in hydrometallurgy (Marklund et al., 2005a, b; Salamova et al., 2014a). In general, there is a considerable variation in the physical and chemical properties of OPEs. As shown in Table S1, these chemicals exhibit a wide range of logKow values (from -0.65 to 9.49). Additionally, OPEs can be classified as semi-volatile compounds with Henry's law constant values ranged from $2.92 \times 10^{-10}$ to

\footnotetext{
* Corresponding author. State Key Laboratory of Environmental Chemistry and Ecotoxicology, Research Centerfor Eco-Environmental Sciences, Chinese Academy of Sciences, Beijing, 100085, China.

E-mail address: caiyaqi@rcees.ac.cn (Y. Cai).
}

$1.98 \times 10^{-8} \mathrm{~atm} \mathrm{~m}^{3} \mathrm{~mol}^{-1}$ (Wensing et al., 2005). Although the atmospheric half-lives of OPEs are below 2 days (from $<1$ to $21.3 \mathrm{~h}$ ), their occurrence in precipitation in the North Sea atmosphere and Arctic, indicates that they can undergo long range atmospheric transport (LRAT) (Möller et al., 2012; Shoeib et al., 2014).

Considering that OPEs are generally not chemically bonded to materials, these compounds could be slowly released into surrounding environment by volatilization, leaching and abrasion (Yang et al., 2014). According to previous reports, several OPEs have been detected in the aquatic (Cristale et al., 2013a; MartinezCarballo et al., 2007; Venier et al., 2014), terrestrial (David and Seiber, 1999; Fries and Mihajlovic, 2011; Mihajlovic and Fries, 2012), and atmospheric environment (Möller et al., 2012; Möller et al., 2011; Salamova et al., 2014b). Additionally, potential adverse effects of OPEs to the ecosystem and human health have also been pointed out in previous studies (Kim et al., 2011; Meeker et al., 2013; Reemtsma et al., 2008). The reports associated with human exposure have demonstrated the reduction of sperm counts and hormone levels due to the exposure to TPhP and TDCP (Meeker and Stapleton, 2010). TCEP and TDCP are considered as carcinogens and potential neurotoxicants (Cequier et al., 2015; Salamova et al., 2014a), and may cause acute or chronic adverse effects to aquatic 
organisms (Cristale et al., 2013a; Kim et al., 2011). TCPP is also a suspected carcinogen (Reemtsma et al., 2008), and TnBP has neurotoxic properties after chronic exposure (Reemtsma et al., 2008). TPhP and 2-ethylhexyl diphenyl phosphate (EHDPP) reveal potentially bioaccumulative and toxic role to aquatic ecosystem (Kim et al., 2011; Sundkvist et al., 2010).

The occurrence and fate of OPEs in aquatic environment is of concern since these compounds can massively reach surface water from industrial and domestic sewage discharge (Fries and Puttmann, 2003; Martinez-Carballo et al., 2007) and atmosphere deposition (Bacaloni et al., 2008; Möller et al., 2011; Regnery and Püttmann, 2009). The discharge of industrial and domestic sewage is considered as the major source of OPEs in surface water (Reemtsma et al., 2008). Some alkyl-OPEs such as trimethyl phosphate (TMP) and triethyl phosphate (TEP), have been well removed in sewage treatment plants (STPs), whereas the chlorinated-OPEs are not subjected to the significant removal, which are, thus, discharged with effluents into rivers (Bester, 2005; Marklund et al., 2005a; Meyer and Bester, 2004). Besides, atmosphere deposition has been pointed to be another important source of OPEs in surface water environment (Möller et al., 2011; Regnery and Püttmann, 2009). The OPEs at levels from ng $\mathrm{L}^{-1}$ to $\mu \mathrm{g} \mathrm{L}^{-1}$ have been detected in many rivers in Germany (Andresen et al., 2004; Fries and Puttmann, 2001, 2003; Regnery and Puttmann, 2010), Aire River in UK (Cristale et al., 2013a), volcanic lakes in Italy (Bacaloni et al., 2008), and rivers in Austria (Martinez-Carballo et al., 2007), as well several rivers in China (Wang et al., 2015, 2014, 2011).

Considering the widely application of OPEs in buildings, vehicles, electronics and plastics, more consumption of these compounds was expected in urban city, especially in large city with a dense population, and the urban surface water may suffer serious contamination of OPEs. So far, only one study focused on the occurrence and distribution of OPEs in urban surface water from Germany (Regnery and Puttmann, 2010), hence, more information should be collected to fill our knowledge gaps of the occurrence and distribution of OPEs in urban surface water from densely populated cities. Moreover, temporal variation of OPEs in aquatic environment should be further investigated since the seasonal trend was uncertain in previous studies (Bacaloni et al., 2008; Regnery and Puttmann, 2010).

According to the data from European flame retardants association (EFRA), China is one of the most flame retardants-consuming countries, accounting for approximately $20 \%$ of global consumption (EFRA, 2012). It is estimated that the annual yield of OPEs had reached 70,000 tons in 2007 and was predicted to increase by $15 \%$ annually in China (Wei et al., 2015). Accordingly, their universal usages may lead to widespread pollution of OPEs in China.

Beijing is one of the most populated and developed cities in China, with total dimension of $16410.54 \mathrm{~km}^{2}$ and a huge population of 21.516 million. The aim of this study was to investigate the occurrence and distribution of OPEs in urban surface water from densely populated city. To this end, levels of 14 OPEs in surface water covering almost the whole urban of Beijing, China were studied. Besides, spatial distribution and seasonal variation from July 2013 to June 2014 of the target compounds in surface water were also investigated. Additionally, sewage influent and effluent, rainwater and road runoff samples were collected and analyzed as the potential sources of OPEs in surface water. Finally, environmental risk of OPEs in surface water was evaluated to explore the impact of these chemicals on aquatic organisms.

\section{Materials and methods}

\subsection{Materials and reagents}

Seven alkyl phosphates, including TMP, TEP, TnBP, tri-iso-butyl phosphate (TiBP), TBEP, tripropyl phosphate (TPrP) and tri(2ethylhexyl) phosphate (TEHP), and three chlorinated alkyl phosphates (TCEP, TCPP and TDCP), and four aryl phosphates, including TPhP, tri-m-cresyl phosphate (TCrP), cresyl diphenyl phosphate (CDPP) and EHDPP, were obtained from Dr. Ehrenstorfer $\mathrm{GmbH}$ (Germany) as target OPEs, and detailed information was listed in Table S1 (Supplementary material). TMP- $\mathrm{d}_{9}, \mathrm{TEP}_{\mathrm{d}} \mathrm{d}_{15}$ and TPrP- $\mathrm{d}_{21}$ obtained from $\mathrm{C} / \mathrm{D} / \mathrm{N}$ Isotopes Inc. (USA), TnBP- $\mathrm{d}_{27}$ and TPhP- $\mathrm{d}_{15}$ purchased from Cambridge Isotope Laboratories (UK), and TCPP- $\mathrm{d}_{18}$ supported by Toronto Research Chemicals Inc. (Canada) were used as internal standards (IS). HPLC grade acetonitrile and dichloromethane (DCM) were provided by Fisher Scientific (USA). Ultrapure water (18.3 M $\Omega$ ) was produced by a Milli-Q Gradient system (Millipore, Bedford, USA).

Individual stock solution with the concentration of $1000 \mathrm{mg} \mathrm{L}^{-1}$ was prepared in acetonitrile, and mixed stock solution containing all analytes was prepared in acetonitrile at the concentration of $10 \mathrm{mg} \mathrm{\textrm {L } ^ { - 1 }}$. All stock solutions were kept in a $-20{ }^{\circ} \mathrm{C}$ refrigerator. Calibration solutions $\left(0.05-1000 \mu \mathrm{g} \mathrm{L}^{-1}\right)$ used in routine application were prepared in acetonitrile/water (4:6).

\subsection{Sampling}

\subsubsection{Urban surface water}

River and lake water samples were collected at 34 sampling sites in the urban of Beijing monthly from July 2013 to June 2014 (except December 2013 and January 2014 in frozen period). A total of 340 water samples (surface layer, $0.2 \mathrm{~m}$ depth) were obtained in 10 sampling campaigns. In order to fully understand the occurrence of OPEs in surface water in Beijing, all of the major rivers and lakes in the urban areas are included in this study. As shown in Fig. 1, the samples L1-L8 were collected from lakes in various parks. The sampling sites R1-R8 belong to Chang River, and sampling sites R9R11 belong to Tonghui River, while the samples R12-R17 were collected from Liangshui River and its tributaries, and samples R18R21 were collected from Qing River and its tributaries. The rest sampling sites R22-R26 were located at Beixiao River, Xiba River, Liangma River, Baijialou Sewer and Xiaotaihou River, respectively.

\subsubsection{Wastewater}

Additionally, seven STPs (A-G) in the urban of Beijing were also marked in Fig. 1. Influent and effluent water samples were collected as $24 \mathrm{~h}$ composite samples by using automatic samplers with sampling interval of $2 \mathrm{~h}$ from STP A in October 2013. The plant employs conventional activated sludge treatments to remove biologically degradable organic materials, and the secondary effluent was discharged into the Qing River.

\subsubsection{Rain water}

A total of 10 rain water samples were collected from June to August 2013 using a stainless steel box (area $1 \mathrm{~m}^{2}$, height $30 \mathrm{~cm}$ ) placed at monitoring station in Beijing teaching botanical garden. This sampling site located in the central urban of Beijing, which near the sampling site L4.

\subsubsection{Road runoff water}

A total of 43 road runoff samples were collected at 5 sampling sites at the main road of Beijing (the 2nd ringroad, 3rd ringroad and 4th ringroad) from June to August 2013. On each occasion, one composite road runoff sample was obtained using a 40-L stainless steel container below the road storm sewer from each site.

All of water samples were collected in glass bottles $(500 \mathrm{~mL})$ rinsed with methanol and dried in advance. Immediately after being transported to the laboratory, the samples were stored at $4{ }^{\circ} \mathrm{C}$ and treated by SPE within two days. Before SPE procedure, water 


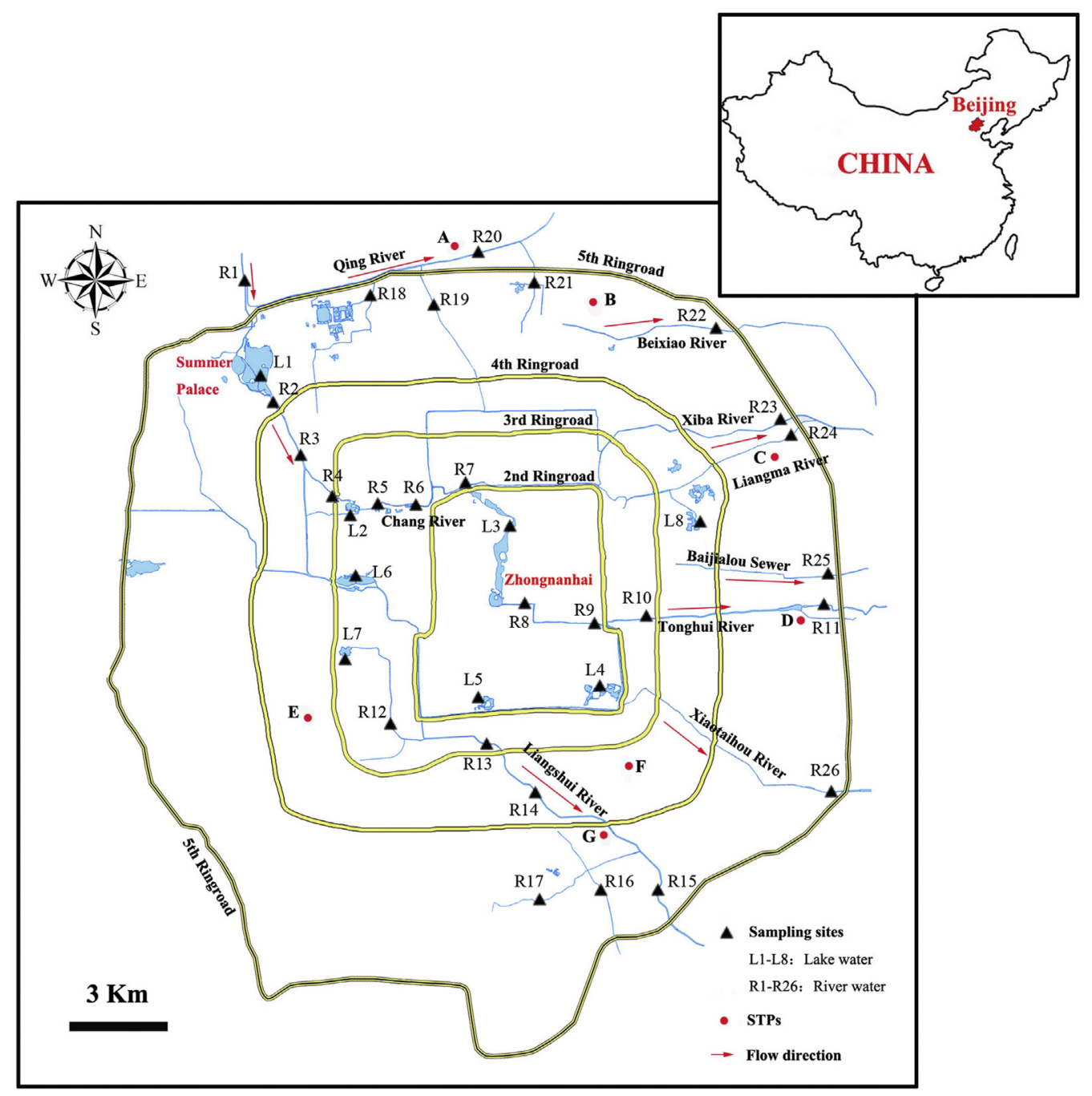

Fig. 1. Sampled points and sewage treatment plants (STPs) in Urban Beijing, China.

samples were filtered through GF/C glass fiber filters $(1.2 \mu \mathrm{m}$, Whatman, UK) to remove suspended particulate matters.

\subsection{Methods}

OPEs were analyzed by an Ultimate 3000 HPLC system (ThermoFisher, USA) coupled with an API 3200 triple-quadrupole mass spectrometer equipped with an electrospray ion source (ESI) (Applied Biosystems/MDS SCIEX, USA). The separation of the analytes was carried out on Acclaim Mixed-Mode HILIC-1 column $(2.1 \mathrm{~mm} \times 150 \mathrm{~mm}$; i.d., $5.0 \mu \mathrm{m})$ (ThermoFisher, USA) at a flow rate of $0.25 \mathrm{~mL} \mathrm{~min}^{-1}$. Ultrapure water (A) and acetonitrile (B) were applied as mobile phase with the gradient as follows: initial $40 \% \mathrm{~B}$ with the maintenance for $1.0 \mathrm{~min}$, sequential linear increase to $60 \% \mathrm{~B}$ in $4 \mathrm{~min}$; following increase to $100 \% \mathrm{~B}$ in $3 \mathrm{~min}$ and hold for $7 \mathrm{~min}$; then, the gradient return to the initial condition of $40 \% \mathrm{~B}$ in $0.2 \mathrm{~min}$ and hold for $6.8 \mathrm{~min}$ to allow for equilibration. The electrospray ionization was operated in the positive ion mode under multiple reaction monitoring (MRM) with the ion spray voltage of $5.0 \mathrm{kv}$ and source temperature of $600{ }^{\circ} \mathrm{C}$. Individual MS/MS parameters for each compound are listed in Table S2 (Supplementary material).

Water samples were extracted and cleaned by solid phase extraction (SPE) with an ENVI-18 cartridge ( $6 \mathrm{ml}, 500 \mathrm{mg}$, Supelco). Cartridges were conditioned with $5 \mathrm{~mL}$ of acetonitrile and $5 \mathrm{~mL}$ of ultrapure water sequentially. Then, $200 \mathrm{~mL}$ of water samples were passed through at a flow rate of $4 \mathrm{~mL} \mathrm{~min}{ }^{-1}$. The cartridges were rinsed with $10 \mathrm{~mL}$ of ultrapure water, dried for $30 \mathrm{~min}$, and finally eluted with $6 \mathrm{~mL}$ of $25 \% \mathrm{DCM}$ in acetonitrile. The eluent was finally concentrated down to approximately $0.4 \mathrm{~mL}$ at $37^{\circ} \mathrm{C}$ under a stream of $\mathrm{N}_{2}$ and diluted to a final volume of $1 \mathrm{~mL}$ with ultrapure water.

\subsection{Quality control}

As shown in Table S3 (Supplementary material), the calibration curves were measured for all 14 OPEs with constant amount of IS (10 ng), and a good linearity ( $R=0.9877-0.9969)$ was obtained for the analytes in a wide concentration range. The limits of detection (LODs, $\mathrm{S} / \mathrm{N} \geq 3$ ) ranged from 0.3 to $16 \mathrm{ng} \mathrm{L}^{-1}$ after extraction of $200 \mathrm{~mL}$ of water sample. The recovery rate of $68.5-113.2 \%$ was observed for river water samples, with the RSD lower than $15 \%$ $(\mathrm{n}=4)$, and recovery rate of $64.8-103.9 \%$ was detected for wastewater samples, with the RSD lower than $15.9 \%(n=4)$. The low recovery rates of some OPEs may be due to their tendency to volatilize or adsorb onto bottles during the sample pretreatment procedure. The application of IS could compensate for these loss to some extent.

Five field blank samples made from ultrapure water $(1 \mathrm{~L})$ was included in river water, lake water, wastewater, rainwater and road runoff sampling and shipped back to the laboratory with the 
samples. Additionally, during the analysis of each batch of samples, at least one lab procedure blank should be prepared from ultrapure water. Six OPEs, including TEP, TCEP, TCPP, TnBP, TiBP and TBEP, were detected in the lab procedure blanks with concentrations lower than $10 \mathrm{ng} \mathrm{L}^{-1}$. While the concentrations of TEP, TCEP and TCPP, when detected, in field blanks were in the range of $5-25 \mathrm{ng} \mathrm{L}^{-1}$. Therefore, results for all analytes were blank corrected by subtraction of mean blank values from the raw OPEs values in water samples. In addition, in order to monitor the stability of the system, a $10 \mu \mathrm{g} \mathrm{L}^{-1}$ standard was set as the quality control concentration and checked every 10 injections.

\subsection{Risk characterization}

The risk of OPEs for aquatic organisms was evaluated by the determination of risk quotient (RQ) values, as described by several previous reports (Cristale et al., 2013a; Li et al., 2012; Sanchez-Avila et al., 2012; Santos et al., 2007). RQ value of each compound in water was calculated using the following formula:

$\mathrm{RQ}=\mathrm{MEC} / \mathrm{PNEC}$

$\mathrm{PNEC}=\left(\mathrm{LC}_{50}\right.$ or $\left.\mathrm{EC}_{50}\right) / f$

Where MEC is the measured environmental concentration; PNEC is the predicted no effect concentration; $\mathrm{LC}_{50}$ or $\mathrm{EC}_{50}$ is the lowest median effective concentration value obtained from available literature, and $f$ is an appropriate standard assessment factor. In this study, the toxicological data $\left(\mathrm{LC}_{50}\right.$ or $\left.\mathrm{EC}_{50}\right)$ for algae, crustacean and fish obtained from available literature, and an assessment factor of 1000 was used for RQ calculation (European Commission, 2003).

In risk assessment studies, common criteria for risk levels are established by interpreting $\mathrm{RQ}$ values: $\mathrm{RQ}<0.1$ indicates low risk to aquatic organisms; $0.1 \leq \mathrm{RQ} \leq 1$ indicates medium risk; $\mathrm{RQ} \geq 1$ indicates high risk (Hernando et al., 2006; Van Doorslaer et al., 2014; Verlicchi et al., 2012).

\section{Results and discussion}

\subsection{Levels of OPEs in urban surface water}

All of 14 OPEs were detected in river and lake water samples in the urban of Beijing, and the total OPEs ( $\sum$ OPEs) varied between

Table 1

Levels ( $\mathrm{ng} \mathrm{L}^{-1}$ ) of OPEs in urban surface water samples in Beijing, China.

\begin{tabular}{lclclr}
\hline Analytes & Mean & Median & Max. & Min. & Fre. $(\%)$ \\
\hline TMP & 144 & 48.3 & 9497 & $<$ LOD $^{\mathrm{a}}$ & 88.2 \\
TEP & 88.7 & 47.5 & 2072 & $<$ LOD & 94.7 \\
TPrP & 0.02 & $<$ LOD & 3.59 & $<$ LOD & 1.4 \\
TCEP & 219 & 104 & 5698 & $<$ LOD & 95.8 \\
TPhP & 4.49 & 1.31 & 96.3 & $<$ LOD & 74.8 \\
TCPP & 291 & 174 & 1742 & $<$ LOD & 99.4 \\
CDPP & 0.43 & 0.03 & 4.85 & $<$ LOD & 48.5 \\
EHDPP & 0.38 & $<$ LOD & 40.3 & $<$ LOD & 6.7 \\
TCrP & 0.18 & $<$ LOD & 4.29 & $<$ LOD & 37.5 \\
TBEP & 116 & 22.8 & 3617 & $<$ LOD & 90.2 \\
TDCP & 46.3 & 23.2 & 855 & $<$ LOD & 79.8 \\
TEHP & 0.91 & $<$ LOD & 23.5 & $<$ LOD & 41.7 \\
TnBP & 19.6 & 10.1 & 256 & $<$ LOD & 84.9 \\
TiBP & 23.3 & 14.1 & 169 & $<$ LOD & 93.6 \\
Alkyl-OPEs & 392 & 218 & 9761 & 0.21 & \\
Cl-OPEs & 556 & 323 & 6537 & $<$ LOD & \\
Aryl-OPEs & 5.48 & 1.82 & 96.3 & $<$ LOD & \\
Total & 954 & 569 & 10,945 & 3.24 & \\
\hline
\end{tabular}

a Concentration below the limit of detection (LOD).
3.24 and $10,945 \mathrm{ng} \mathrm{L}^{-1}$ (Table 1), which is significantly higher than those detected in lake water samples from less populated cities of Germany (Regnery and Puttmann, 2010), reflecting heavy anthropogenic impacts on the contamination of OPEs in urban surface water from densely populated city. The concentration-percent composition of 14 OPEs in the surface water in this study was shown in Fig. S1. TCPP and TCEP were the most abundant compounds, and their concentration-percent composition ([TCPP]+ [TCEP]) accounted for $28.2-83.1 \%$ of the total, with an average of 56.7\%. The result can be expected giving that TCPP and TCEP are widely used in flexible and rigid polyurethane foam (PUF), rubber and textile coatings (Marklund et al., 2003, 2005a). Additionally, the chlorinated OPEs were reported to be more persistent in the environment than the non-chlorinated OPEs (Reemtsma et al., 2008). Then, TMP, TEP and TBEP were the secondary abundant OPEs in surface water, and their concentration-percent composition $([\mathrm{TMP}]+[\mathrm{TEP}]+[\mathrm{TBEP}])$ accounted for $11.6-63.2 \%$ of the total, with an average of $34.1 \%$.

In the present study, TCPP, TCEP, TMP, TEP and TBEP were detected with the frequency of $80-99 \%$ in the river and lake water in Beijing (Table 1). As summarized in Table 2, most of these levels were higher than those detected in rivers around the Bohai Sea, China (Wang et al., 2015), Oder River (Fries and Puttmann, 2003), Elbe River (Bollmann et al., 2012) and lake water samples (Regnery and Puttmann, 2010) from Germany, as well as those in surface water from Austria (Martinez-Carballo et al., 2007), Rhine River in Netherlands (Bollmann et al., 2012) and volcanic lake waters from central Italy (Bacaloni et al., 2008). TCEP concentration in surface water from Beijing was similar to that detected in Songhua River (Wang et al., 2011) and Pearl River Estuaries, China (Wang et al., 2014), and the levels of TCPP and TBEP in this study were similar to those detected in the Spanish rivers (Cristale et al., 2013b) and Pearl River Estuaries, China (Wang et al., 2014), but the TCPP level was lower than that in Aire River in UK (Cristale et al., 2013a).

Two structural isomers, TnBP and TiBP, were observed at similar average levels of $19.6\left(<\right.$ LOD-256) and $23.3\left(<\right.$ LOD-169) $\mathrm{ng} \mathrm{L}^{-1}$, and detection frequency of $85 \%$ and $94 \%$, respectively. These concentrations were similar to those detected in rivers around the Bohai Sea, China (<LOD-218 ng L ${ }^{-1}$ ) (Wang et al., 2015), Danube River (20-110 ng L $\left.{ }^{-1}\right)$, Schwechat River (82 $\mathrm{ng} \mathrm{L}^{-1}$ ) and Liesig River (75 ng L ${ }^{-1}$ ) in Austria (Martinez-Carballo et al., 2007), Elbe River (2-50 $\mathrm{ng} \mathrm{L}^{-1}$ ) (Bollmann et al., 2012) and urban lake waters (<LOQ$122 \mathrm{ng} \mathrm{L}^{-1}$ ) (Regnery and Puttmann, 2010) in Germany, but lower than those detected in Songhua River, Northeast China (87-960 $\mathrm{ng} \mathrm{L}^{-1}$ ) (Wang et al., 2011), rivers in Spain (<LOD$1200 \mathrm{ng} \mathrm{L}^{-1}$ ) (Cristale et al., 2013b), Albano lake in Italy (<LOQ$784 \mathrm{ng} \mathrm{L}^{-1}$ ) (Bacaloni et al., 2008) and other rivers in Germany (100-1510 ng L ${ }^{-1}$; 69-1044 ng L ${ }^{-1}$ ) (Fries and Puttmann, 2001, 2003).

TPhP was detected with the frequency of $75 \%$ and average concentration of $4.49\left(<\right.$ LOD-96.3) $\mathrm{ng} \mathrm{L}^{-1}$ in urban surface water in Beijing, which was similar to those detected in most of other sites (Andresen et al., 2004; Cristale et al., 2013a; Martinez-Carballo et al., 2007; Wang et al., 2011). In good agreement with literature, TPrP, TEHP, TCrP, CDPP and EHDPP were found with low concentration $\left(<\right.$ LOD-40.3 $\left.\mathrm{ng} \mathrm{L}^{-1}\right)$ and frequency $(<50 \%)$ in the surface water in Beijing. However, high concentration of $951 \mathrm{ng} \mathrm{L}^{-1}$ for TPrP was detected in Vico lake in Italy (Bacaloni et al., 2008), implying the different production and application patterns of OPEs in different areas.

\subsection{Spatial variation}

Mann-Whitney's tests were used for statistical analysis to investigate the spatial variance of concentrations for OPEs. Five 
Table 2

Concentrations (ng L $\mathrm{L}^{-1}$ ) of selected OPEs in different studies in surface water.

\begin{tabular}{|c|c|c|c|c|c|c|c|c|c|}
\hline Sites & TEP & TCEP & ТCPP & TDCP & TBEP & TnBP & TiBP & TPhP & Ref. \\
\hline Surface water, Beijing & $\begin{array}{l}88.7\left(<\text { LOD }^{\mathrm{a}}-\right. \\
2072)\end{array}$ & $\begin{array}{l}219(<\text { LOD- } \\
5698)\end{array}$ & $\begin{array}{l}291(<\text { LOD- } \\
1742)\end{array}$ & $\begin{array}{l}46.3(<\text { LOD- } \\
855)\end{array}$ & $\begin{array}{l}116(<\text { LOD- } \\
3617)\end{array}$ & $\begin{array}{l}19.6 \\
(<\text { LOD- } \\
256)\end{array}$ & $\begin{array}{l}23.3 \\
(<\mathrm{LOD}- \\
169)\end{array}$ & $\begin{array}{l}4.49 \\
(<\text { LOD- } \\
96.3)\end{array}$ & This study \\
\hline $\begin{array}{l}\text { Rivers around Bohai Sea, } \\
\text { China }\end{array}$ & n.a. ${ }^{\text {b }}$ & $1-268$ & $5-921$ & $<$ LOD-44 & $<$ LOD-47 & $<$ LOD-81 & $\begin{array}{l}<\text { LOD- } \\
218\end{array}$ & $<$ LOD-16 & (Wang et al., 2015) \\
\hline $\begin{array}{l}\text { Pearl River Estuaries, } \\
\text { China }\end{array}$ & n.a. & $220-1160$ & $150-1150$ & n.a. & n.a. & n.a. & n.a. & n.a. & (Wang et al., 2014) \\
\hline Songhua River, China & n.a. & $38-3700$ & $5-190$ & $2-46$ & $5-310$ & $87-960$ & n.a. & $5-65$ & (Wang et al., 2011) \\
\hline Five great lakes & n.a. & 1.5 & 12 & 4 & 74.9 & 2.2 & n.a. & 1.2 & (Venier et al., 2014) \\
\hline Aire river, UK & n.a. & $119-316$ & $113-26050$ & $62-149$ & n.a. & n.a. & n.a. & $6.3-22$ & (Cristale et al., 2013a) \\
\hline $\begin{array}{l}\text { Navarra, Asturias, } \\
\text { Catalonia, Spain }\end{array}$ & n.a. & $<$ LOD-330 & $<$ LOD-1800 & $<$ LOD-200 & $<$ LOD -4600 & $\begin{array}{l}<\text { LOD- } \\
370\end{array}$ & $\begin{array}{l}<\text { LOD- } \\
1200\end{array}$ & $<$ LOD-18 & (Cristale et al., 2013b) \\
\hline Elbe river, Germany & $6.99-33.9$ & $5-20$ & $40-250$ & $6.4-30.8$ & $<$ LOD-80 & $2-7.5$ & $10-50$ & $0.3-4$ & (Bollmann et al., 2012) \\
\hline Rhine Delta, Netherlands & $29.7-82.7$ & $12-25$ & $75-160$ & $13.2-30.6$ & $28-54$ & $6-28$ & $17-84$ & $1-2$ & (Bollmann et al., 2012) \\
\hline $\begin{array}{l}\text { Urban lake water, } \\
\text { Germany }\end{array}$ & n.a. & 23,61 & 85,126 & n.a. & $<\mathrm{LOQ}^{\mathrm{C}}, 53$ & 32,17 & 10,8 & n.a. & $\begin{array}{l}\text { (Regnery and Puttmann, } \\
\text { 2010) }\end{array}$ \\
\hline Volcanic Lakes, Italy & $1-42$ & $<$ LOD-64 & $2-62$ & $2-60$ & $8-127$ & $3-784$ & $1-380$ & $2-21$ & (Bacaloni et al., 2008) \\
\hline Surface water, Austria & $13-51$ & $13-130$ & $33-170$ & $7-19$ & $24-500$ & $20-110$ & n.a. & $6-10$ & $\begin{array}{l}\text { (Martinez-Carballo et al., } \\
\text { 2007) }\end{array}$ \\
\hline Ruhr river, Germany & n.a. & $13-130$ & $20-200$ & n.a. & $<40$ & n.a. & n.a. & $10-200$ & (Andresen et al., 2004) \\
\hline Oder river, Germany & n.a. & $<$ LOD-1236 & n.a. & n.a. & $121-952$ & $69-1044$ & n.a. & n.a. & $\begin{array}{l}\text { (Fries and Puttmann, } \\
\text { 2003) }\end{array}$ \\
\hline Surface water, Germany & n.a. & $<$ LOD-220 & n.a. & n.a. & $103-663$ & $\begin{array}{l}100 \\
-1510\end{array}$ & n.a. & n.a. & $\begin{array}{l}\text { (Fries and Puttmann, } \\
\text { 2001) }\end{array}$ \\
\hline
\end{tabular}

a Concentration below the limit of detection (LOD).

b Not available.

c Concentration below the limit of quantification (LOQ).

target compounds, including TPrP, EHDPP, TCrP, TEHP and CDPP, were not evaluated due to their low detection frequencies $(<50 \%)$. In this study, statistical analysis revealed that significant differences were observed in the $\sum$ OPEs concentrations among different sampling sites $(\mathrm{p}<0.05)$. As illustrated in Fig. 2, the levels of OPEs detected in all lakes were similar to those detected in the Chang River ( $p>0.05$ ), but much lower than those detected in other rivers $(\mathrm{p}<0.05)$. In general, the lakes and Chang River are used for leisure and entertainment, where the discharge of wastewater and surface runoff were strictly controlled (Hou et al., 2013). Furthermore, the upstream of the Chang River and some lakes (site L1-L3) is an important drinking water source for Beijing residents, and has been protected by the fence. On the contrary, the other rivers (except Chang River) are usually located near the outlet of STPs, and flow through a densely populated and highly industrialized urban area in Beijing, which may be heavily impacted by large amounts of STP effluents and industrial wastewaters. Therefore, the different sources and functions of the surface water contributed to the different levels of OPEs in the lakes and rivers.

As for the rivers (except Chang River), no significant difference of $\sum$ OPEs concentrations was observed for Tonghui River, Liangshui River and Qing River ( $\mathrm{p}>0.05$ ), whereas the three rivers present significant lower levels than the other rivers located in the eastern urban $(\mathrm{p}<0.05)$. As shown in Fig. 2, the highest concentrations of TMP was detected in Xiaotaihou River (R26), which were almost $1-2$ orders of magnitudes higher than those detected in other rivers. TMP is very polar and volatile OPE with the log Kow of -0.65 and vapor pressure of $8 \times 10^{-1}$ torr at $25{ }^{\circ} \mathrm{C}$ (Reemtsma et al., 2008); it was found to be well removed in sewage treatment process (84-100\%) (Marklund et al., 2005a). Therefore, the high level of TMP in Xiaotaihou River may be due to other point sources, which needs to be further investigated. In addition, the highest level of TBEP was detected in Baijialou Sewer (R25), followed by Tonghui River (R11). TBEP was widely used in floor polish and floor waxes, and has been frequently detected in wastewater with the concentration up to 35,000 and $30,000 \mathrm{ng} \mathrm{L}^{-1}$ in influent and effluent samples (Marklund et al., 2005a), respectively. It is known that the site R11 in Tonghui River situated at the downstream of STP D which is the greatest STP in Beijing with the treatment capacity of $1000000 \mathrm{~m}^{3} \mathrm{~d}^{-1}$. And the Baijialou Sewer may receive directly discharge of untreated domestic sewage from nearby residents. Therefore, the high levels of TBEP in Baijialou Sewer and Tonghui River may be due to the heavy discharge of domestic sewage.

The chlorinated-OPEs were detected in Qing River, Tonghui River, Liangshui River and other rivers in the eastern urban with high concentrations, and the highest level was detected in Xiba River (R23). Chlorinated-OPEs are mainly used as flame retardants in polyurethane foam (PUF) and rubber in domestic, public, and automotive products, as well as used in textile coatings (Abdallah and Covaci, 2014; van der Veen and de Boer, 2012). TCPP and TCEP are also the most abundant OPEs in influents of STPs, and even detected with higher concentration in effluents, suggesting their persistence in water (Bester, 2005; Marklund et al., 2005a; Meyer and Bester, 2004). So the ubiquitous occurrence of the chlorinated-OPEs in rivers may be explained by the widespread use of chlorinated-OPEs-containing products and their resistance to degradation. TPhP was the most frequently detected aryl-OPEs in this study, and the highest concentration was detected in Liangshui River (R14). In previous studies, TPhP has been frequently detected in STP influent and effluent samples with concentrations below 300 ng L ${ }^{-1}$ (Marklund et al., 2005; Martinez-Carballo et al., 2007; Meyer and Bester, 2004). Thus, the relatively high concentration of TPhP in Liangshui River is presumably attributed to the effluent discharge of STP E and F along this river.

Geographically, higher levels of OPEs were observed in the rivers located at eastern and southern urban of Beijing, where the STPs are mainly distributed. For instance, the sampling site R11 located at the downstream of STP D, accordingly, the levels of TCPP and TCEP were approximately twofold of those detected at the upstream sampling site (R10). In this study, the concentrations of OPEs were also analyzed in influent and effluent samples in one typical STP (STP A). As shown in Table 3, TCPP revealed the highest concentration of $465 \mathrm{ng} \mathrm{L}^{-1}$ in the influent, followed by TBEP 


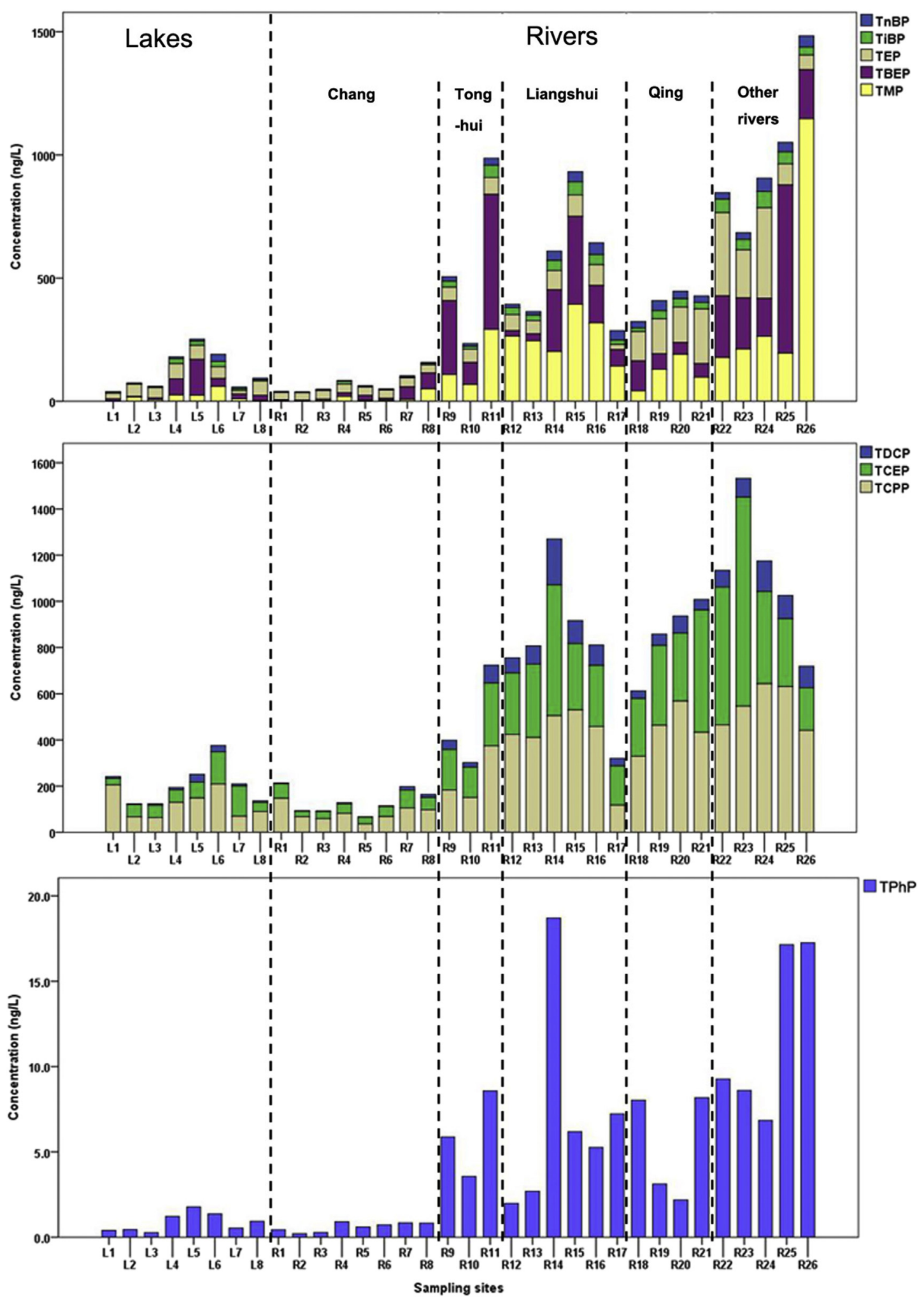

Fig. 2. Concentrations of OPEs in different lakes and rivers from Beijing.

(398 ng L $\mathrm{L}^{-1}$ ), TCEP (150 ng L ${ }^{-1}$ ) and TnBP (120 ng L $\left.{ }^{-1}\right)$. Corresponding levels for TCPP, TBEP, TCEP and TnBP in the effluent were $605,103,254$ and $93.1 \mathrm{ng} \mathrm{L}^{-1}$, respectively. The high concentration of these pollutants in the influent and effluent samples seems to confirm our conjecture that treated and untreated sewage discharge is one of the important factors contributed to relatively high levels of OPEs in the surface water in eastern and southern urban of Beijing. Besides, it is expected that the surface water system in eastern and southern urban located in the downstream area will suffer more serious pollution of OPEs as rivers flow 
Table 3

Levels (ng L $\mathrm{L}^{-1}$ ) of OPEs in influent, effluent, rainwater and road runoff samples in Beijing, China.

\begin{tabular}{|c|c|c|c|c|c|c|c|c|}
\hline \multirow[t]{2}{*}{ Analytes } & \multicolumn{2}{|l|}{ STP A } & \multicolumn{3}{|c|}{ Rainwater (mean) } & \multicolumn{3}{|c|}{ Road runoff (mean) } \\
\hline & Influent & Effluent & $\begin{array}{l}\text { June } \\
(n=3)\end{array}$ & $\begin{array}{l}\text { July } \\
(n=3)\end{array}$ & August $(\mathrm{n}=4)$ & $\begin{array}{l}\text { June } \\
(n=11)\end{array}$ & $\begin{array}{l}\text { July } \\
(\mathrm{n}=12)\end{array}$ & August $(\mathrm{n}=20)$ \\
\hline TMP & 17.2 & 44.9 & 217 & 221 & 150 & 183 & 271 & 156 \\
\hline TEP & 46.9 & 64.1 & 107 & 85.8 & 81.9 & 239 & 348 & 226 \\
\hline TCEP & 150 & 254 & 3560 & 2270 & 2592 & 941 & 716 & 337 \\
\hline $\mathrm{TPhP}$ & 15.4 & 6.20 & 0.88 & 1.77 & 2.59 & 50.0 & 38.1 & 33.6 \\
\hline ТСРP & 465 & 605 & 366 & 224 & 183 & 1488 & 1578 & 846 \\
\hline CDPP & $<\mathrm{LOD}^{\mathrm{a}}$ & $<$ LOD & $<$ LOD & $<$ LOD & $<$ LOD & 16.5 & 11.1 & 9.37 \\
\hline TCrP & 0.2 & $<$ LOD & $<$ LOD & $<$ LOD & $<$ LOD & 0.85 & 1.23 & 0.79 \\
\hline TBEP & 398 & 103 & 2.23 & 7.58 & 4.79 & 175 & 186 & 154 \\
\hline TDCP & 87.0 & 82.5 & $<$ LOD & $<$ LOD & $<$ LOD & 242 & 109 & 71.5 \\
\hline TEHP & 7.10 & $<$ LOD & 0.61 & 0.82 & 1.38 & 7.38 & 7.07 & 6.64 \\
\hline TnBP & 120 & 93.1 & 12.8 & 17.4 & 19.4 & 78.5 & 86.2 & 73.2 \\
\hline TiBP & 54.0 & 66.5 & 19.1 & 9.60 & 9.67 & 59.0 & 69.1 & 45.0 \\
\hline
\end{tabular}

a Concentration below the limit of detection (LOD).

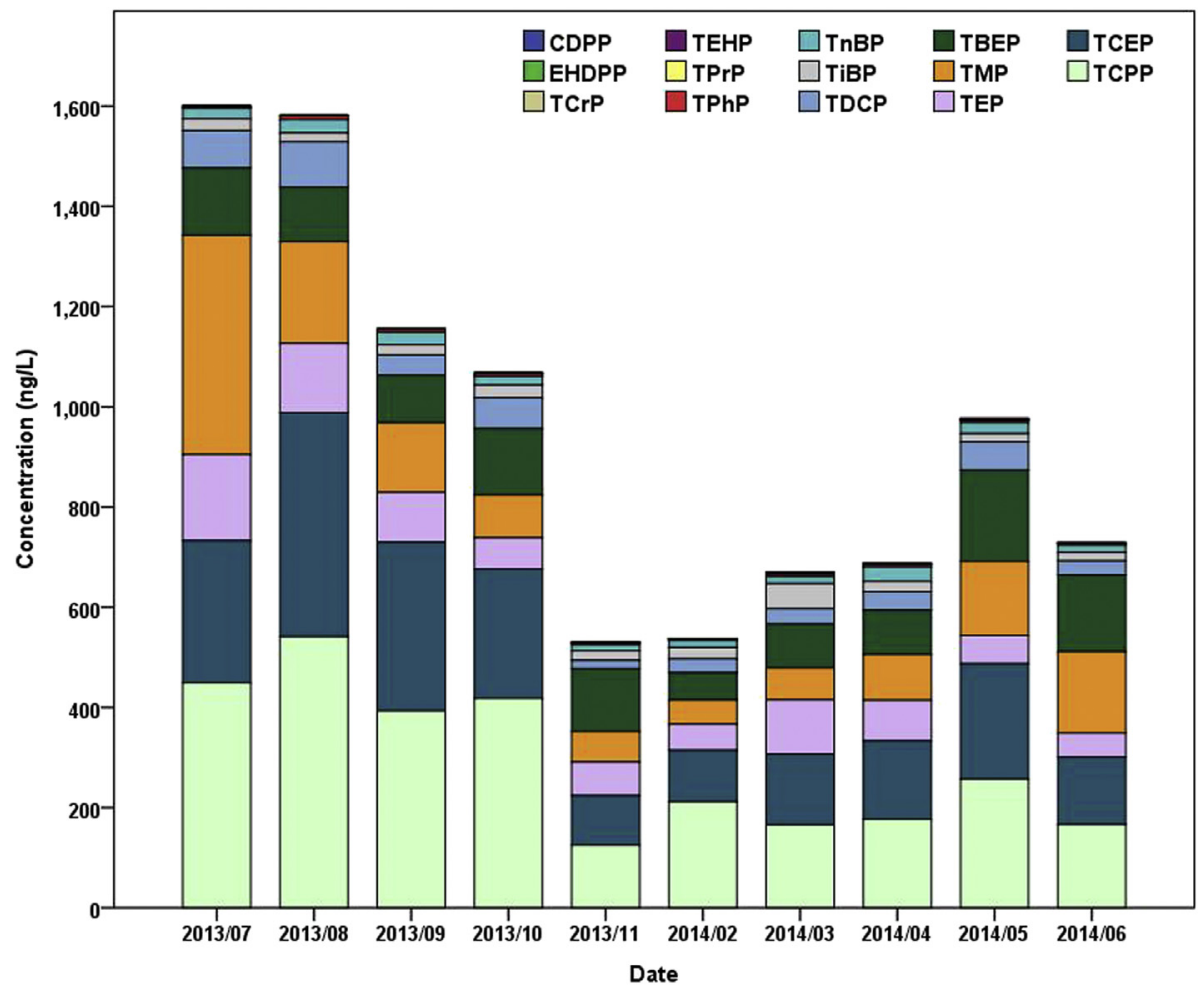

Fig. 3. Seasonal variation of OPEs in urban surface water from July 2013 to June 2014.

through Beijing from west to east, especially for the chlorinated OPEs that are supposed to be persistent in aquatic environment.

\subsection{Seasonal variation}

The statistical analysis (Friedman's test) showed that the concentration of OPEs in urban surface water is significantly different from season to season depending on individual compound $(\mathrm{p}<0.05)$. The samples collected in the summer (July and August) showed higher levels of total OPEs, TCPP, TCEP, TMP and TEP, while lower levels of OPEs were detected during the winter (November and February) (Fig. 3). This result disagreed with previous study showing no significant seasonal trends for the OPEs in urban lake water samples from Germany (Regnery and Puttmann, 2010). It has been previously demonstrated that the proportions of OPEs in condensate and internal vehicle air reveal an increase when the temperature is increased (Regnery and Püttmann, 2009). The average temperature is about $30^{\circ} \mathrm{C}$ in July and August (summer) in Beijing, while it is only about $10{ }^{\circ} \mathrm{C}$ and $5{ }^{\circ} \mathrm{C}$ in November and February (winter), respectively. Therefore, higher emission of OPEs, especially the more volatile OPEs (TMP, TEP, TCEP and TCPP etc.), from vehicles and buildings in summer than in winter can be expected.

In addition, high levels and detection frequency of OPEs have been observed in outdoor environment, including air particle matters (Möller et al., 2012; Salamova et al., 2014a, 2014b) and dust (Cao et al., 2014). It is probable that these pollutants in the outdoor air and dust are released into rivers along with wet deposition (rainfall) in the summer. Beijing is located in the north of China, with a temperate territorial semi-humid climate, and the most of precipitation occurs during the summer from July to August (Ren et al., 2013). Therefore, the high concentration of OPEs in urban 
Table 4

Risk quotients (RQs) for the aquatic organisms as calculated from measured environmental concentrations (MECs) and predicted environmental concentrations (PNECs).

\begin{tabular}{|c|c|c|c|c|}
\hline Analytes & Organisms & $\begin{array}{l}\mathrm{L}(\mathrm{E}) \mathrm{C}_{50}{ }^{\mathrm{a}} \\
\left(\mathrm{mg} \mathrm{L}^{-1}\right)\end{array}$ & $\begin{array}{l}\text { PNEC } \\
\left(\mathrm{ng} \mathrm{L}^{-1}\right)\end{array}$ & RQs \\
\hline \multirow[t]{3}{*}{ TCEP } & Algae (Scenedesmus subspicatus) & 51 & 51,000 & $0-0.1117$ \\
\hline & Crustacean (Daphnia magna) & 330 & 330,000 & $0-0.0173$ \\
\hline & Fish (Carassius auratus) & 90 & 90,000 & $0-0.0633$ \\
\hline \multirow[t]{3}{*}{ TCPP } & Algae (Scenedesmus subspicatus) & 45 & 45,000 & $0-0.0387$ \\
\hline & Crustacean (Daphnia magna) & 91 & 91,000 & $0-0.0192$ \\
\hline & Fish (Poecilia reticulata) & 30 & 30,000 & $0-0.0581$ \\
\hline \multirow[t]{3}{*}{ TDCP } & Algae (Pseudokirchneriella subcapitata) & 39 & 39,000 & $0-0.0219$ \\
\hline & Crustacean (Daphnia magna) & 4.2 & 4200 & $0-0.2036$ \\
\hline & Fish (Carassius auratus) & 5.1 & 5100 & $0-0.1677$ \\
\hline \multirow[t]{3}{*}{ TnBP } & Algae (Scenedesmus subspicatus) & 4.2 & 4200 & $0-0.0609$ \\
\hline & Crustacean (Daphnia magna) & 3.65 & 3650 & $0-0.0701$ \\
\hline & Fish (Carassius auratus) & 8.8 & 8800 & $0-0.0291$ \\
\hline \multirow[t]{3}{*}{ TiBP } & Algae (Scenedesmus subspicatus) & 34 & 34,000 & $0-0.0050$ \\
\hline & Crustacean (Daphnia magna) & 11 & 11,000 & $0-0.0153$ \\
\hline & Fish (Leuciscus idus) & 20 & 20,000 & $0-0.0084$ \\
\hline \multirow[t]{3}{*}{ TEP } & Algae (Scenedesmus subspicatus) & 900 & 900,000 & $0-0.0023$ \\
\hline & Crustacean (Daphnia magna) & 350 & 350,000 & $0-0.0059$ \\
\hline & Fish (Leuciscus idus) & 2140 & $2,140,000$ & $0-0.0010$ \\
\hline \multirow[t]{3}{*}{ TBEP } & Algae (Scenedesmus subspicatus) & & & \\
\hline & Crustacean (Daphnia magna) & 75 & 75,000 & $0-0.0482$ \\
\hline & Fish (Pimephales promelas) & 13 & 13,000 & $0-0.2782$ \\
\hline \multirow[t]{3}{*}{$\mathrm{TPhP}$} & Algae (Scenedesmus subspicatus) & 0.5 & 500 & $0-0.1925$ \\
\hline & Crustacean (Daphnia magna) & 1 & 1000 & $0-0.0963$ \\
\hline & Fish (Carassius auratus) & 0.7 & 700 & $0-0.1375$ \\
\hline \multirow[t]{3}{*}{$\mathrm{TCrP}$} & Algae (Scenedesmus subspicatus) & 0.29 & 290 & $0-0.0148$ \\
\hline & Crustacean (Daphnia magna) & 0.27 & 270 & $0-0.0159$ \\
\hline & Fish (Lepomis macrochirus) & 0.11 & 110 & $0-0.0390$ \\
\hline
\end{tabular}

a Acute toxicity (LC50 or EC50) data are obtained from (Verbruggen et al., 2005).

surface water in July and August may be due to the input of rainwater enriching OPEs from the outdoor air and dust in the summer.

In this study, the concentrations of OPEs were also analyzed in rainwater and road runoff samples in Beijing from June to August (Table 3). TDCP was not detected in rainwater samples and TBEP was only detected in rainwater at low concentration level (2.23-7.58 $\mathrm{ng} \mathrm{L}^{-1}$ ), whereas the levels of TDCP and TBEP were up to 71.5-242 and 154-175 $\mathrm{ng} \mathrm{L}^{-1}$, respectively, in road runoff samples. Similar result was also obtained for TnBP, TiBP and TPhP in rainwater and road runoff samples, suggesting that these OPEs possibly come from road dust rather than outdoor air. Compared to sewage effluent, much higher levels of TCPP, TCEP, TMP and TEP were detected in rainwater and road runoff samples (Table 3), demonstrating the great contribution of rainfall to the presence of OPEs in urban surface water. The concentrations of TCEP detected in rainwater (2270-3560 $\mathrm{ng} \mathrm{L}^{-1}$ ) and TCPP detected in road runoff (846-1578 ng $\mathrm{L}^{-1}$ ) were even one order of magnitude higher than those detected in STP effluent. This fact further confirms our hypothesis that wet deposition (rainfall) is an important factor for the high levels of OPEs in the surface water of Beijing in the summer.

\subsection{Risk assessment}

The continuous inputs and potential toxicity of OPEs have drawn an increasing concern on their effects towards the ecosystem. In this study, the risk assessment to aquatic organisms was estimated for the most frequently detected OPEs, including TEP, TCEP, TCPP, TDCP, TBEP, TPhP, TnBP, TiBP and TCrP, in urban surface water of Beijing.

Acute median effective concentrations $\left(\mathrm{LC}_{50}\right.$ or $\left.\mathrm{EC}_{50}\right)$ of 9 OPEs to different aquatic organisms (algae, crustacean and fish) were obtained from the Environmental Risk Limits report for organophosphorus flame retardants (Verbruggen et al., 2005). As shown in Table 4 , low $(\mathrm{RQ}<0.1)$ or medium risk $(0.1 \leq \mathrm{HQ} \leq 1)$ of 9 OPEs was observed for three organisms in urban surface water from Beijing.
TBEP showed the highest RQ of 0.2782 for fish, and TDCP and TPhP present the highest RQ of 0.2036 and 0.1925 for crustacean and algae, respectively. The sum of RQs varied from 0.00001 to 0.2885 for algae, from 0.00009 to 0.3479 for crustacean, and from 0.0001 to 0.3766 for fish, respectively, suggesting the low or medium risk associated with the combinatorial effects of these OPEs in aquatic environment.

By comparing with RQ values of PBDEs (0.0013 and 0.0017) in the river of Shanghai, China (Zhao et al., 2012), higher RQ values of OPEs (maximum: 0.2782 for TBEP) were observed in the rivers of Beijing. Therefore, the risk of OPEs in rivers in Beijing should be of concern. In addition, the presence of OPEs in biota samples has been reported previously (Kim et al., 2011; Sundkvist et al., 2010), including TEHP, EHDPP, TPhP and TnBP, even the hydrophilic TEP $($ LogKow $=0.80)$ and TCPP $(\operatorname{LogKow}=2.59)$ with low octanol-water partition coefficients (Reemtsma et al., 2008). Therefore, bioaccumulation and biomagnification of OPEs in biota from aquatic environment should be further investigated for a more comprehensive risk assessment.

\section{Conclusion}

In the present study, the occurrence and distribution of 14 OPEs in urban surface water of Beijing, China were explored. All of 14 OPEs were detected in the urban surface water samples, and TCEP and TCPP were the most abundant compounds followed by TMP, TEP and TBEP. The levels of these compounds in urban surface water in Beijing were higher than or similar to those detected in most of other sites in literature.

Spatial distribution of OPEs in urban surface water was also studied. Relatively high concentrations of OPEs were detected in other river samples than those detected in all lake waters and Chang River. Among several rivers, higher levels of OPEs were detected in the rivers located in southern and eastern urban of Beijing, which was probably due to the treated and untreated 
sewage discharge. Additionally, seasonal variation in the concentrations of OPEs in urban surface water was also observed, which revealed higher contamination in the summer (July and August). The high levels of OPEs detected in rainwater and road runoff samples (June to August) demonstrated that wet deposition was an important factor responsible for the high levels of OPEs in surface water in the summer season. Risk assessment based on acute toxicity data suggested the low or medium risk of OPEs to three aquatic organisms (algae, crustacean and fish). However, taking into account the high levels of OPEs in several sites in Beijing, longterm exposure and bioaccumulation of these pollutants in aquatic environment should be further explored.

\section{Acknowledgments}

This work was financially supported by the High-Tech Research and Development Program of China (2013AA065201), the National Natural Science Foundation of China (No. 21537004, 21477143, 21321004, and 21407008) and the Strategic Priority Research Program of the Chinese Academy of Sciences (XDB14010201).

\section{Appendix A. Supplementary data}

Supplementary data related to this article can be found at http:// dx.doi.org/10.1016/j.envpol.2015.11.008.

\section{References}

Abdallah, M.A., Covaci, A., 2014. Organophosphate flame retardants in indoor dust from Egypt: implications for human exposure. Environ. Sci. Technol. 48, 4782-4789.

Andresen, J.A., Grundmann, A., Bester, K., 2004. Organophosphorus flame retardants and plasticisers in surface waters. Sci. Total Environ. 332, 155-166.

Bacaloni, A., Cucci, F., Guarino, C., Nazzari, M., Samperi, R., Lagana, A., 2008. Occurrence of organophosphorus flame retardant and plasticizers in three volcanic lakes of Central Italy. Environ. Sci. Technol. 42, 1898-1903.

Bester, K., 2005. Comparison of TCPP concentrations in sludge and wastewater in a typical German sewage treatment plant - comparison of sewage sludge from 20 plants. J. of Environ. Monit. 7, 509-513.

Bollmann, U.E., Moler, A., Xie, Z.Y., Ebinghaus, R., Einax, J.W., 2012. Occurrence and fate of organophosphorus flame retardants and plasticizers in coastal and marine surface waters. Water Res. 46, 531-538.

Cao, Z., Xu, F., Covaci, A., Wu, M., Wang, H., Yu, G., Wang, B., Deng, S., Huang, J., Wang, X., 2014. Distribution patterns of brominated, chlorinated, and phosphorus flame retardants with particle size in indoor and outdoor dust and implications for human exposure. Environ. Sci. Technol. 48, 8839-8846.

Cequier, E., Sakhi, A.K., Marce, R.M., Becher, G., Thomsen, C., 2015. Human exposure pathways to organophosphate triesters - a biomonitoring study of mother-child pairs. Environ. Int. 75, 159-165.

Cristale, J., Katsoyiannis, A., Sweetman, A.J., Jones, K.C., Lacorte, S., 2013a. Occurrence and risk assessment of organophosphorus and brominated flame retardants in the river Aire (UK). Environ. Pollut. 179, 194-200.

Cristale, J., Vazquez, A.G., Barata, C., Lacorte, S., 2013b. Priority and emerging flame retardants in rivers: occurrence in water and sediment, Daphnia magna toxicity and risk assessment. Environ. Int. 59, 232-243.

David, M.D., Seiber, J.N., 1999. Analysis of organophosphate hydraulic fluids in US Air Force base soils. Archives Of Environ. Contam. Toxicol. 36, 235-241.

European Commission, 2003. Technical Guidance Document on Risk Assessment in Support of Commission Directive 93/67/EEC on Risk Assessment for New Notified Substances, Commission Regulation (EC) No 1488/94 on Risk Assessment for Existing Substances, Directive 98/8/EC of the European Parliament and of the Council Concerning the Placing of Biocidal Products on the Market. Part II.

European Flame Retardants Association(EFRA), 2012. Keeping Fire in Check in Building and Construction. March. http://www.cefic-efra.com/.

Fries, E., Mihajlovic, I., 2011. Pollution of soils with organophosphorus flame retardants and plasticizers. J. of Environ. Monit. 13, 2692-2694.

Fries, E., Puttmann, W., 2001. Occurrence of organophosphate esters in surface water and ground water in Germany. J. of Environ. Monit. 3, 621-626.

Fries, E., Puttmann, W., 2003. Monitoring of the three organophosphate esters TBP TCEP and TBEP in river water and ground water (Oder, Germany). J. of Environ. Monit. 5, 346-352.

Hernando, M.D., Mezcua, M., Fernandez-Alba, A.R., Barcelo, D., 2006. Environmental risk assessment of pharmaceutical residues in wastewater effluents, surface waters and sediments. Talanta 69, 334-342.

Hou, P.Q., Ren, Y.F., Zhang, Q.Q., Zhang, Y., Wang, H.F., Lu, F., Zhang, H.X., Ouyang, Z.Y., Wang, X.K., 2013. Temporal and spatial variations of water quality in a trans-urban river in Beijing, China. Fresenius Environ. Bull. 22, 561-572. Kim, J.W. Isobe, T. Chang, K.H. Amano, A., Maneja, R.H., Zamora, P.B., Siringan, F.P., Tanabe, S., 2011. Levels and distribution of organophosphorus flame retardants and plasticizers in fishes from Manila Bay, the Philippines. Environ. Pollut. 159, 3653-3659.

Li, W.H., Shi, Y.L., Gao, L.H., Liu, J.M., Cai, Y.Q., 2012. Occurrence of antibiotics in water, sediments, aquatic plants, and animals from Baiyangdian Lake in North China. Chemosphere 89, 1307-1315.

Marklund, A., Andersson, B., Haglund, P., 2003. Screening of organophosphorus compounds and their distribution in various indoor environments. Chemosphere 53, 1137-1146.

Marklund, A., Andersson, B., Haglund, P., 2005a. Organophosphorus flame retardants and plasticizers in Swedish sewage treatment plants. Environ. Sci. Technol. 39, 7423-7429.

Marklund, A., Andersson, B., Haglund, P., 2005b. Traffic as a source of organophosphorus flame retardants and plasticizers in snow. Environ. Sci. Technol. 39, 3555-3562.

Martinez-Carballo, E., Gonzalez-Barreiro, C., Sitka, A., Scharf, S., Gans, O., 2007. Determination of selected organophosphate esters in the aquatic environment of Austria. Sci. Total Environ. 388, 290-299.

Meeker, J.D., Cooper, E.M., Stapleton, H.M., Hauser, R., 2013. Urinary metabolites of organophosphate flame retardants: temporal variability and correlations with house dust concentrations. Environ. Health Perspect. 121, 580-585.

Meeker, J.D., Stapleton, H.M., 2010. House dust concentrations of organophosphate flame retardants in relation to hormone levels and semen quality parameters. Environ. Health Perspect. 118, 318-323.

Meyer, J., Bester, K., 2004. Organophosphate flame retardants and plasticisers in wastewater treatment plants. J. of Environ. Monit. 6, 599-605.

Mihajlovic, I., Fries, E., 2012. Atmospheric deposition of chlorinated organophosphate flame retardants (OFR) onto soils. Atmos. Environ. 56, 177-183.

Möller, A., Sturm, R., Xie, Z., Cai, M., He, J., Ebinghaus, R., 2012. Organophosphorus flame retardants and plasticizers in airborne particles over the Northern Pacific and Indian Ocean toward the polar Regions: evidence for global occurrence. Environ. Sci. Technol. 46, 3127-3134.

Möller, A., Xie, Z.Y., Caba, A., Sturm, R., Ebinghaus, R., 2011. Organophosphorus flame retardants and plasticizers in the atmosphere of the North Sea. Environ. Pollut. 159, 3660-3665.

Reemtsma, T., Quintana, J.B., Rodil, R., Garcia-Lopez, M., Rodriguez, I., 2008. Organophosphorus flame retardants and plasticizers in water and air I. Occurrence and fate. Trac Trends Anal. Chem. 27, 727-737.

Regnery, J., Puttmann, W., 2010. Occurrence and fate of organophosphorus flame retardants and plasticizers in urban and remote surface waters in Germany. Water Res. 44, 4097-4104.

Regnery, J., Püttmann, W., 2009. Organophosphorus flame retardants and plasticizers in rain and snow from middle Germany. Clean. Soil, Air, Water 37, $334-342$.

Ren, Y., Xu, Z., Zhang, X., Wang, X., Sun, X., Ballantine, D.J., Wang, S., 2013. Nitrogen pollution and source identification of urban ecosystem surface water in Beijing. Front. Environ. Sci. Eng. 8, 106-116.

Salamova, A., Hermanson, M.H., Hites, R.A., 2014a. Organophosphate and halogenated flame retardants in atmospheric particles from a European Arctic site. Environ. Sci. Technol. 48, 6133-6140.

Salamova, A., Ma, Y., Venier, M., Hites, R.A., 2014b. High levels of organophosphate flame retardants in the Great Lakes atmosphere. Environ. Sci. Technol. Lett. 1, $8-14$.

Sanchez-Avila, J., Tauler, R., Lacorte, S., 2012. Organic micropollutants in coastal waters from NW Mediterranean Sea: sources distribution and potential risk. Environ. Int. 46, 50-62.

Santos, J.L., Aparicio, I., Alonso, E., 2007. Occurrence and risk assessment of pharmaceutically active compounds in wastewater treatment plants. A case study: Seville city (Spain). Environ. Int. 33, 596-601.

Shoeib, M., Ahrens, L., Jantunen, L., Harner, T., 2014. Concentrations in air of organobromine, organochlorine and organophosphate flame retardants in Toronto, Canada. Atmos. Environ. 99, 140-147.

Sundkvist, A.M., Olofsson, U., Haglund, P., 2010. Organophosphorus flame retardants and plasticizers in marine and fresh water biota and in human milk. J. Of Environ. Monit. 12, 943-951.

van der Veen, I., de Boer, J., 2012. Phosphorus flame retardants: properties, production, environmental occurrence, toxicity and analysis. Chemosphere 88, 1119-1153.

Van Doorslaer, X., Dewulf, J., Van Langenhove, H., Demeestere, K., 2014. Fluoroquinolone antibiotics: an emerging class of environmental micropollutants. Sci. Total Environ. 500-501, 250-269.

Venier, M., Dove, A., Romanak, K., Backus, S., Hites, R., 2014. Flame retardants and legacy chemicals in great lakes' water. Environ. Sci. Technol. 48, 9563-9572.

Verbruggen, E.M.J., Rila, J.P., Traas, T.P., Posthuma-Doodeman, C.J.A.M. Posthumus, R., 2005. Environmental Risk Limits for Several Phosphate Esters, with Possible Application as Flame Retardant. RIVM report 601501024.

Verlicchi, P., Al Aukidy, M., Zambello, E., 2012. Occurrence of pharmaceutica compounds in urban wastewater: removal, mass load and environmental risk after a secondary treatment-A review. Sci. Total Environ. 429, 123-155.

Wang, R.M., Tang, J.H., Xie, Z.Y., Mi, W.Y., Chen, Y.J., Wolschke, H., Tian, C.G., Pan, X.H., Luo, Y.M., Ebinghaus, R., 2015. Occurrence and spatial distribution of organophosphate ester flame retardants and plasticizers in 40 rivers draining into the Bohai Sea, north China. Environ. Pollut. 198, 172-178. 
Wang, X.W., He, Y.Q., Lin, L., Zeng, F., Luan, T.G., 2014. Application of fully automatic hollow fiber liquid phase microextraction to assess the distribution of organophosphate esters in the Pearl River Estuaries. Sci. Total Environ. 470, 263-269.

Wang, X.W., Liu, J.F., Yin, Y.G., 2011. Development of an ultra-high-performance liquid chromatography-tandem mass spectrometry method for high throughput determination of organophosphorus flame retardants in environmental water. J. Chromatogr. A 1218, 6705-6711.

Wei, G.L., Li, D.Q., Zhuo, M.N., Liao, Y.S., Xie, Z.Y., Guo, T.L., Li, J.J., Zhang, S.Y., Liang, Z.Q., 2015. Organophosphorus flame retardants and plasticizers: sources, occurrence, toxicity and human exposure. Environ. Pollut. 196, 29-46.

Wensing, M., Uhde, E., Salthammer, T., 2005. Plastics additives in the indoor environment - flame retardants and plasticizers. Sci. Total Environ. 339, 19-40.

Yang, F., Ding, J., Huang, W., Xie, W., Liu, W., 2014. Particle size-specific distributions and preliminary exposure assessments of organophosphate flame retardants in office air particulate matter. Environ. Sci. Technol. 48, 63-70.

Zhao, H., Meng, X., XIiang, N., Li, Y., Wen, Z., Chen, L., 2012. Ecological risk assessment of polybrominated diphenyl ethers in river receiving wastewater in Shanghai. Environ. Chem. 31, 573-579. 